\title{
Estudos acadêmicos contemporâneos sobre políticas culturais no Brasil: análises e tendências
}

\author{
Estudios académicos sobre las políticas culturalesen Brasil: \\ análisis y tendencias
}

\section{Contemporary academic studies about cultural policies in Brazil: analyses and tendencies}

\author{
Lia Calabre ${ }^{1}$
}

\section{Palavras chave: \\ Políticas culturais \\ Estudos acadêmicos - tendências em políticas culturais}

Mapeamento

\section{Resumo:}

As políticas culturais no Brasil somente se tornaram efetivamente objeto de estudos acadêmicos a partir dos primeiros anos do século XXI. A cultura é um tradicional objeto de trabalho acadêmico, em especial em estudos da antropologia, ou da sociologia, ou ainda formando outros subcampos de conhecimento como o da história cultural, da geografia cultural e da própria antropologia cultural, só para citar alguns exemplos. Algumas das mudanças de análise que ocorreram nas últimas décadas estão ligadas aos novos papéis atribuídos à cultura, mais especificamente, nas sociedades contemporâneas. A proposta deste artigo é a de mapear e analisar, de maneira amostral, algumas das tendências recentes presentes nos estudos acadêmicos sobre políticas culturais. Como essa área está sendo configurada? Em que campos do conhecimento tal problemática vem sendo trabalhada? Em que regiões do país esses estudos mais se evidenciam? 
Resumen:

Políticas culturales en Brasil sólo se convirtieron en objetos de estudios académicos en los primeros años del siglo XXI. La cultura es un objeto de trabajo académico tradicional, sobre todo en los estudios de la antropología o la sociología, o la formación de otros sub-campos de conocimiento como la historia de la cultura, la geografía cultural y la propia antropología cultural, sólo para nombrar unos pocos. Algunos de los análisis de los cambios que se han producido en las últimas décadas están vinculados a las nuevas funciones asignadas a la cultura, más específicamente, en las sociedades contemporáneas. El propósito de este artículo es analizar algunas de las tendencias recientes presentes en los estudios académicos sobre las políticas culturales. Ya que esta zona se está creando? En lo que se ha trabajado las áreas del conocimiento de estos problemas? ¿En qué regiones del país se hicieron la mayoría de estos estudios?

\section{Keywords:}

Cultural policies

Academic studies trend in cultural policies

Mapping

\section{Abstract:}

Cultural policies in Brazil have effectively become a topic for academic studies since the first years of the 21 st Century. Culture is traditionally a topic of academic research, especially in anthropology, or sociology or yet constituting other sub-areas of knowledge, like cultural history, cultural geography and cultural anthropology itself - just to mention a few examples. Some of the changes in the analysis that have occurred in the last decades are linked to the new roles specifically attributed to culture in contemporary societies. This article proposes to map and analysesamples of the recent tendencies found in academic studies about cultural policies. How is this area being set up? Which are the fields of knowledge in which these issues are addressed? Which are the regions of the country in which such studies are more prominent? 


\section{Estudos acadêmicos contemporâneos sobre políticas culturais no Brasil: análises e tendências}

As políticas culturais no Brasil somente se tornaram efetivamente objeto de estudos acadêmicos a partir dos primeiros anos do século XXI. A proposta deste artigo é a de mapear e analisar, de maneira amostral, algumas das tendências recentes presentes nos estudos acadêmicos sobre políticas culturais. Como essa área está sendo configurada? Em que campos do conhecimento tal problemática vem sendo trabalhada? Em que regiões do país esses estudos mais se evidenciam? São algumas das questões impulsionadoras que deram origem ao artigo.

A cultura é um tradicional objeto de trabalho acadêmico, em especial em estudos da antropologia, ou da sociologia, ou ainda formando outros subcampos de conhecimento como o da história cultural, da geografia cultural e da própria antropologia cultural, só para citar alguns exemplos. As linguagens artísticas têm seu campo disciplinar próprio há mais de um século. Algumas das mudanças de análise que ocorreram nas últimas décadas estão ligadas aos novos papéis atribuídos a cultura, mais especificamente, nas sociedades contemporâneas. Enfim, a questão central aqui proposta é a de compor um quadro analítico - em uma versão ainda inicial e exploratória - sobre a problemática da cultura estudada como uma área de políticas públicas.

Historicamente a relação entre a cultura e o Estado esteve assentada sobre a problemática da distinção, do agregado simbólico identificador de poder e riqueza, ou seja, tanto mais rico e poderoso era um Estado quanto mais ele podia sustentar seus artistas. O mesmo se passava com as classes dominantes, tanto mais poderosos os senhores, os burgueses, os comerciantes ou os empresários quanto mais podiam manter a prática do mecenato e constituir suas coleções de arte.

Essa relação entre o estado/ sociedade/ cultura, ao longo dos séculos XIX e XX foi sendo transformada. Chegamos à segunda metade do século XX com a cultura passando a integrar o campo dos direitos fundamentais e, logo, o das obrigações do estado em relação ao conjunto dos cidadãos. Tal trajetória que foi cruzada pelos autoritarismos, assim como pelos nacionalismos e pela indústria cultural, até chegar, mais contemporaneamente - em especial no pós $2^{\mathrm{a}}$ Guerra Mundial - à questão da cidadania cultural dentro de um ambiente democrático que visa a garantir o direito à cultura.

Voltamos então ao ponto inicial desse artigo: como vem sendo construído o campo de estudos das relações entre estado, cultura e políticas públicas?

Logo de início é importante demarcar o recorte do campo que vai ser trabalhado. Se é verdade que a produção de conhecimento extrapola os limites do campo acadêmico, também é verdade que é dentro da academia que há a possibilidade da dedicação de dois a quatro anos de estudo a um objeto específico, muitas vezes financiados através de bolsas de estudos, contando com ambientes e ferramentas próprias para tal trabalho. Esse é um investimento público na produção de conhecimento, cujos resultados formam a base de parte significativa das informações disponíveis sobre os mais diversos campos e que, em geral, possui um bom grau de autonomia em relação aos objetos estudados. Os resultados de tais investigações estão sistematizados em dissertações e teses e vêm sendo 
disponibilizas em bancos de dados acessíveis ao público em geral.

Buscando responder à indagação acima, foram trabalhadas informações oriundas do que se pode denominar de três conjuntos documentais distintos. A base de teses e dissertações da Coordenação de Aperfeiçoamento de Pessoal de Nível Superior (Capes), os trabalhos apresentados no Encontro de Estudos Multidisciplinares em Cultura - Enecult, no GT de Políticas Culturais, e nos trabalhos inscritos para o Seminário Internacional de Políticas Culturais na Fundação Casa de Rui Barbosa, nos anos de 2010 ede 2012 - ambos encontros trabalham a partir a seleção de textos completos de professores e de estudantes de pós-graduação.

O Enecult, que teve início em 2004, é realizado pela Universidade Federal da Bahia, pelo Centro de Estudos Multidisciplinares em Cultura (CULT) ${ }^{2}$ e pelo Instituto de Humanidades, Artes e Ciências prof. Milton Santos (IHAC) ${ }^{3}$. O Enecult rapidamente se tornou uma referência para aqueles que estudam as políticas culturais em geral. O Seminário Internacional de Políticas Culturais, realizado pelo setor de estudos de políticas culturais da Fundação Casa de Rui Barbosa, teve início em 2006, inicialmente como encontro de especialistas para discutir especificamente o campo das políticas culturais. Em 2010, o Seminário passou a receber inscrições de artigos completos de estudantes de pós-graduação para as mesas de comunicações. Há a exigência de que o recorte específico dos trabalhos incida sobre políticas culturais.

No caso da base Capes, foram trabalhados os resumos disponíveis na base, através de uma pesquisa por assunto e por termos fechados: política cultural, políticas culturais, políticas públicas de cultura, ao longo de todo o período disponível na mesma (1987 a 2012) ${ }^{4}$. Foram também trabalhos, a título de comparação (e teste) as expressões: leis de incentivo, financiamento à cultura e Ministério da Cultura. Essa também foi uma estratégia utilizada para compreender a lógica da indexação e da própria ferramenta de busca, ainda que devamos ressaltar que a Capes não interfere na escolha das palavras chaves, os trabalhos são conduzidos em seus formatos originais para a base de dados.

Aqui algumas questões preliminares devem ser destacadas. A primeira delas diz respeito à ferramenta de busca na base que, algumas vezes, deixa escapar termos presentes nas palavras chave mas que, por outro lado, os captura em outros campos como no corpo dos resumos. Logo, para obter uma amostra mais rigorosa teriam que ter sido utilizados vários indexadores para cercar a temática, como uma espécie de pesquisa booleana, estratégia que foi inviabilizada pela retirada da base completa do ar por parte da Capes $^{5}$. Tais problemas não invalidam a amostra mas não geram resultados completamente satisfatórios.

O segundo conjunto estudado é o dos trabalhos aprovados para apresentação nos GTs sobre Políticas Culturais do Enecult e coletados a partir do CD Rom que contém os anais do evento, para estabelecer um diálogo com o terceiro conjunto (o dos trabalhos do Seminário da FCRB) foram trabalhados os anais do VI (2010) e do VIII (2012) Enecults.Todos os trabalhos são submetidos a um GT e avaliados por uma comissão de seleção. A filiação dos trabalhos ao campo das políticas culturais é feita pelos próprios autores dos artigos, na medida em que eles têm uma oferta múltipla de GTs temáticos para direcionarem as propostas de comunicação. Como pode ser observado na tabela abaixo: 
Tabela 1 - Listagem das seções temáticas - Enecult - 2010-2012

\begin{tabular}{|c|c|c|c|}
\hline Seções Temáticas & 2010 & 2011 & 2012 \\
\hline Consumo e públicos culturais & $\mathrm{x}$ & & \\
\hline Cultura(s) $)^{7}$ e América Latina & & $x$ & $X$ \\
\hline Cultura Digital & $x$ & & \\
\hline Cultura (s) e arte (s) & $\mathrm{x}$ & $\mathrm{X}$ & $X$ \\
\hline Cultura e cidade & $x$ & & \\
\hline Cultura, cidade e território & & $\mathrm{X}$ & $\mathrm{X}$ \\
\hline Cultura e desenvolvimento & $x$ & $x$ & $x$ \\
\hline Cultura e identidade & $\mathrm{x}$ & & \\
\hline Cultura e mídia & $x$ & $x$ & $x$ \\
\hline Cultura e música & & $\mathrm{X}$ & $\mathrm{x}$ \\
\hline Cultura e religião & $x$ & & \\
\hline Cultura digital, direito autoral e cultural & & $\mathrm{X}$ & $X$ \\
\hline Cultura, etnicidade e religião & & $x$ & $x$ \\
\hline Cultura, gêneros e sexualidade & & $\mathrm{X}$ & $x$ \\
\hline Direitos autorais e culturais & $x$ & & \\
\hline Formação, gestão e produção cultural & $\mathrm{x}$ & $x$ & $x$ \\
\hline Narrativas audiovisuais & & $\mathrm{x}$ & $x$ \\
\hline Narrativas e perspectivas culturais & $\mathrm{x}$ & & \\
\hline Patrimônio cultural & $x$ & & \\
\hline Patrimônio cultural e memória & & $\mathrm{X}$ & $x$ \\
\hline Políticas culturais & $x$ & $x$ & $x$ \\
\hline
\end{tabular}

Fonte: Anais do Enecult - UFBA - (2010, 2011 e 2012)

O levantamento nos indicou que os temas cultura e arte, cultura e desenvolvimento, cultura e mídia, formação, gestão e produção cultural e o de política cultural estiveram presentes nos três anos selecionados, informação à qual acrescento o dado de que o GT de políticas culturais esteve presente nos 10 anos, recém completados, de realização do Enecult.

Um terceiro conjunto documental analisado - que foi o que motivou inicialmente este estudo - é o dos trabalhos, textos com- pletos, enviados para o Seminário Internacional de Políticas Culturais de FCRB. Nesse caso foi consideradoo conjunto dos trabalhos enviados ao seminário, nos anos de 2010 e de2012, tendo em vista que são especificamente sobre políticas culturais. O seminário nessa modalidade aceita somente trabalhos de pós-graduandos stricto-sensu, mestres, doutores e professores, com uma abertura a partir de 2013 para gestores culturais.

É interessante também assinalar que os trabalhos submetidos aos seminários 
FCRB, assim como os do GT de Políticas Culturais do Enecult, tratam da problemática das políticas culturais, mas que esta pode não ser nem o tema, nem o objeto principal da tese ou da dissertação. Fato este que não invalida a contribuição dos trabalhos para o acúmulo do conhecimento produzido. Ou seja, a construção do campo de estudos das políticas culturais está sendo aqui pensada tanto a partir da produção de dissertações e teses específicas sobre o mesmo, quanto a partir da elaboração de artigos de divulgação científica. Nesse último caso temos, inclusive, a produção de diversos doutores e mestres que não tiveram o tema como objeto de pesquisa ${ }^{8}$.

\section{Apresentação e análise dos dados}

Para uma melhor visualização da conformação do campo procedeu-se a divisão dos dados oriundos da base Capes, em dois períodos. $\mathrm{O}$ primeiro deles abrange os anos de 1988 até $2000^{\circ}$. O primeiro trabalho localizado na base - a partir da busca pelos indexadores - é de 1988 e trata da questão de política de desenvolvimento na esfera do lazer cultural e o segundo, de 1989, trata da questão da relação da política cultural, do patrimônio histórico dos museus e da memória nos espaços urbanos. É importante chamar a atenção para o fato de que ao ser concluída, uma dissertação ou uma tese se iniciou em um período de dois a quatro anos antes (no caso da década de 1980 pode ocorrer até um prazo maior chegando a seis anos de anterioridade), ou seja, aquele pesquisador já está no campo há algum tempo discutindo o objeto de estudo em fóruns e encontros acadêmicos.

A coleta de informações na base Capes foi realizada a partir dos indexadores: política cultural, políticas públicas de cultura, leis de incentivo à cultura, financiamento à cultura e Ministério da Cultura - a busca foi realizada considerando-se as palavras-chave, o título e o resumo, enquadrando o trabalho a partir da prioridade estabelecida pelo próprio autor. E o resultado obtido para o período de 1988 a 2000 , foi o seguinte:

Tabela 2 -Teses e dissertações defendidas no campo das políticas culturais - 1988-2000

\begin{tabular}{|c|c|c|c|c|c|c|c|c|c|c|c|c|c|c|}
\hline & 88 & 89 & 90 & 91 & 92 & 93 & 94 & 95 & 96 & 97 & 98 & 99 & 00 & tot \\
\hline Política cultural & 01 & 01 & - & - & 01 & 01 & 05 & 01 & 02 & - & - & 02 & 02 & 16 \\
\hline $\begin{array}{l}\text { Política pública } \\
\text { de Cultura }\end{array}$ & - & - & - & - & - & - & - & - & - & - & - & - & 02 & 02 \\
\hline Leis de incentivo & - & - & - & - & - & - & - & - & - & - & 01 & - & - & 01 \\
\hline $\begin{array}{l}\text { Financiamento à } \\
\text { cultura }\end{array}$ & - & - & - & - & - & - & - & - & - & - & - & - & - & - \\
\hline $\begin{array}{l}\text { Ministério da } \\
\text { cultura }\end{array}$ & - & - & - & - & - & - & - & - & - & - & - & - & - & - \\
\hline TOTAL & 01 & 01 & - & - & 01 & 01 & 05 & 01 & 02 & - & 01 & 02 & 04 & 19 \\
\hline
\end{tabular}

Fonte: Base Capes - março/2013 
Tendo em vista o fato de que a primeira lei de incentivo à cultura, a Lei Sarney, foi promulgada em 1986, a temática leis de incentivo e financiamento à cultura foram inseridas na busca, frustrando uma expectativa inicial de que em meados dos anos 1990, tivessem sendo defendidas as primeiras teses e dissertações sobre o tema, fato esse que as informações da base Capes não confirmaram. Alguns trabalhos que se tornaram clássicos e de referência, como a tese sobre patrimônio histórico da especialista Maria Cecília Londres Fonseca foram defendidos nesse período. Temos ainda alguns estudos sobre a gestão de Mário de Andrade à frente do Departamento de Cultura de São Paulo, trabalhos comparados e sobre políticas internacionais. Um dado interessante é o de que, já no final da década de 1980, surgem dois trabalhos sobre políticas culturais locais contemporâneas, sinalizando que alguns processos municipais e estaduais estavam em curso.

A segunda tabela foi composta com os dados dos anos de 2001 até 2012. Lembrando que estamos tratando de trabalhos defendidos, a partir de 2005 já podemos identificar algum diálogo entre as ações, discussões e discursosdo Ministério da Cultura, assim como das reformulações e políticas que foram implementadas a partir de $2003 \mathrm{com}$ os temas estudados. O crescimento mais efetivo do campo de estudos vai ocorrer a partir de 2009 .

Tabela 3 - Teses e dissertações defendidas no campo das políticas culturais - 2001-2012

\begin{tabular}{|c|c|c|c|c|c|c|c|c|c|c|c|c|c|}
\hline & 01 & 02 & 03 & 04 & 05 & 06 & 07 & 08 & 09 & 10 & 11 & 12 & total \\
\hline Política cultural & - & 03 & 01 & 03 & - & 02 & 02 & 01 & 01 & 05 & 02 & 01 & 21 \\
\hline $\begin{array}{l}\text { Política pública } \\
\text { de cultura }\end{array}$ & - & - & 01 & 03 & 01 & 02 & 04 & 06 & 08 & 10 & 18 & 17 & 70 \\
\hline Leis de incentivo & 04 & 02 & 02 & 02 & 05 & 02 & 03 & 06 & 04 & 07 & 05 & 05 & 47 \\
\hline $\begin{array}{l}\text { Financiamento à } \\
\text { cultura }\end{array}$ & - & - & - & - & 02 & - & 01 & - & 01 & 03 & - & - & 07 \\
\hline $\begin{array}{l}\text { Ministério da } \\
\text { cultura }\end{array}$ & 02 & 04 & 01 & 03 & 04 & 01 & 02 & 04 & 13 & 07 & 15 & 16 & 72 \\
\hline TOTAL & 06 & 09 & 05 & 11 & 12 & 07 & 12 & 17 & 27 & 32 & 40 & 39 & 217 \\
\hline
\end{tabular}

Fonte: Base Capes - março/2013 
A partir dos dados acima verifica-se claramente a mudança do quadro da produção sobre o tema, onde $92 \%$ dos trabalhos foi produzido entre os anos de 2001 a 2012, ou seja 217 registros de um total de 238. Ao observarmos a tabela vislumbramos um segundo movimento de aceleração de produção que tem início na segunda metade do período, mais especificamente em 2007, ano a partir do qual o aumento do número de trabalhos seguiu uma escala crescente - 54 trabalhos de 2001 a 2006 perfazendo um total de $23 \%$ contra 167 trabalhos defendidos entre 2007 e 2012, alcançando um total de $77 \%$ do período.

Observa-se que há um claro deslocamento das temáticas de política cultural para políticas públicas de cultura. Tal deslocamento não tem um caráter meramente semântico, os trabalhos incorporam e/ ou dialogam com as mudanças conceituais que estão sendo discutidas pela área pública, pelos organismos internacionais e pela própria academia. O indexador "Ministério da Cultura" concentra análises de vários programas e ações implementados pelo mesmo e que não contém palavras-chave como políticas culturais. No quadro síntese abaixo percebe-se o papel que passou a ocupar as ações implementadas pelo Minc a partir do início da gestão do Ministro Gil, em 2003, no contexto dos trabaIhos acadêmicos.

\section{Tabela 4 - Sintese}

\begin{tabular}{|l|l|l|l|l|l|}
\hline & \multicolumn{2}{l}{$1988-2006$} & $2007-2012$ & & Total \\
\hline Política cultural & 25 & $67,6 \%$ & 12 & $34,4 \%$ & 37 \\
\hline Política pública de cultura & 9 & $12,5 \%$ & 63 & $87,5 \%$ & 72 \\
\hline Leis de incentivo & 18 & $37,5 \%$ & 30 & $62,5 \%$ & 48 \\
\hline Financiamento à cultura & 2 & $28,6 \%$ & 5 & $71,4 \%$ & 07 \\
\hline Ministério da cultura & 15 & $20,8 \%$ & 57 & $79,2 \%$ & 72 \\
\hline
\end{tabular}

Fonte: Base Capes - março/2013

O reflexo desse quadro vai ser sentido nos encontros acadêmicos, nos quais trabalhos finalizados e em andamento passam a ser apresentados com maior intensidade, somando-se às pesquisas de alguns desses professores/orientadores/ pesquisadores.

Nos estudos sobre a produção acadêmica não podemos deixar de considerar uma variável importante que é a do próprio crescimento dos programas de pós-graduação que, segundo os dados da Capes, em $2000^{10}$ somavam 1.440 passando em 2012 para $3.342^{11}$. Abaixo, nos dois gráficos produzidos e disponibilizados pela própria Capes, observamos o crescimento dos programas e sua distribuição pelas grandes áreas do conhecimento. 


\section{Gráfico 1 - Distribuição por grande área 2000}

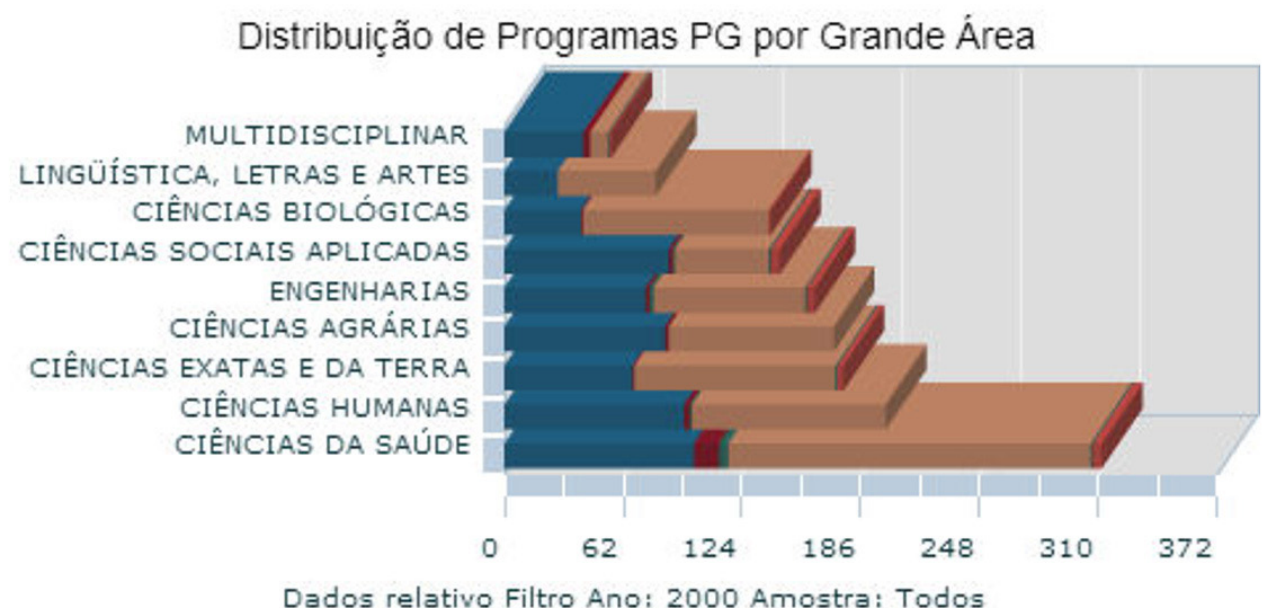

Fonte: GeoCapes

\section{Gráfico 2 - Distribuição por grande área 2012}

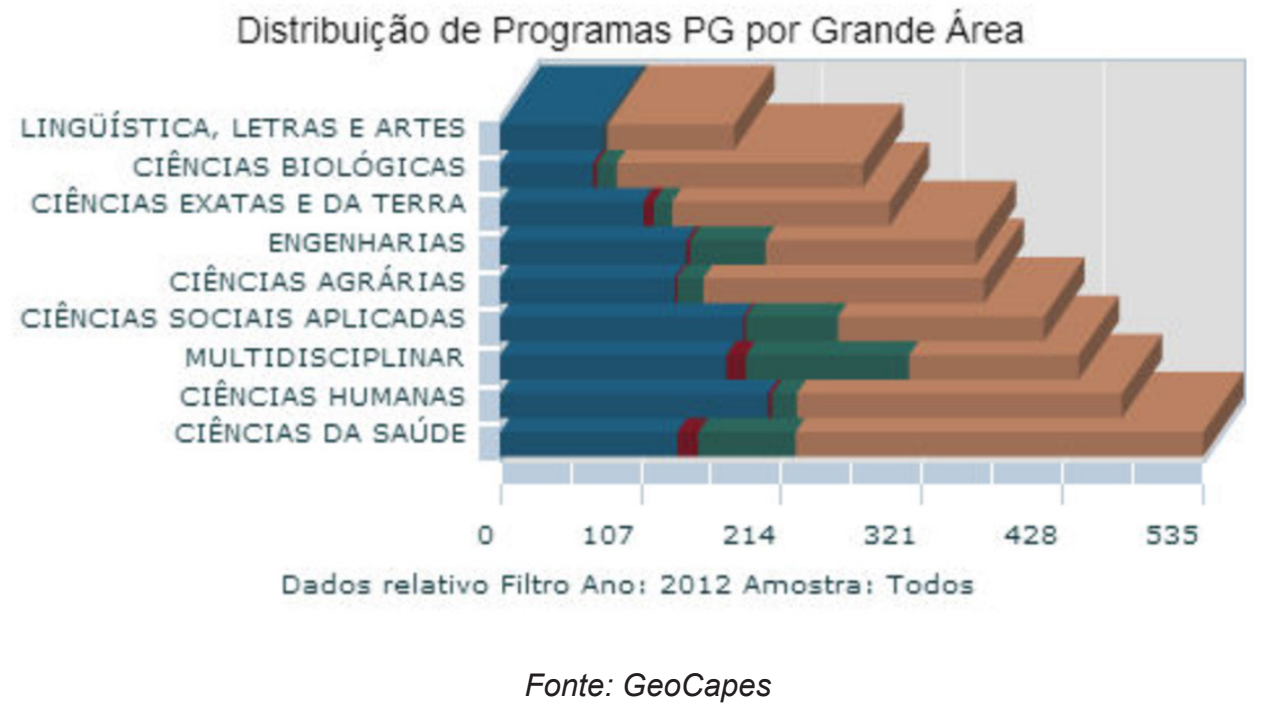

Nos gráficos acima o primeiro campo da barra é o dos programas que possuem somente mestrados, o segundo campo é o dos doutorados, o terceiro campo dos mestrados profissionais e o último campo dos programas que tem mestrado e doutorado. Como podemos perceber o número de programas nas áreas de ciências humanas (de 199 para 433 programas), ciências socias aplicadas (de 144 para
414 programas), tiveram um crescimento significativo, mas o mais expressivo foi do campo multidisciplinar (de 56 para 440 programas). A grande concentração da pós-graduação se mantém na região sudeste ( $45,5 \%$ do total), mais especificamente em São Paulo (762 programas), Rio de Janeiro (405 programas) e Minas Gerais (335 programas). Entretanto, cabe assinalar que os programas mutidisciplinares e de ciên- 
cias humanas e sociais tiveram um grande crescimento nas outras regiões do país.

Passando à análise dos quadros dos trabalhos apresentados nos encontros acadêmicos, é interessante começar expondo a sistemática do funcionamento dos encontros e a realização do recorte dos trabalhos que compuseram a amostra aqui utilizada. No caso do Enecult foram listados os trabalhos integrantes dos grupos temáticos de políticas culturais, os critérios de seleção são estabelecidos pela organização e repassados aos professores avaliadores de cada grupo temático. Existem outros congressos, seminários e encontros que tem grupos de trabalho sobre políticas culturais, mas que, em geral, são mesclados com outras temáticas como é o caso da União Latina de Economia Política da Informação, da Comunicação e da Cultura - Ulepicc que conta com o GT - Políticas Culturais e Eco- nomia Política da Cultura; ou da Reunião de Antropologia do Mercosul - RAM, com o GT - Antropologia, política e gestão pública no campo da cultura, ou o Encontro Internacional de Direitos Culturais com o GT Política Cultural e Fomento à Cultura.

Pela proximidade de seus perfis, os dados do Enecult serão trabalhos junto com os do Seminário Internacional de Políticas Culturais - que é o único evento específico sobre políticas culturais. Nesse último o elemento central das propostas de comunicação deve ser a problemática da política cultural, que pode estar aplicada às mais variadas áreas tais como as artes, economia criativa, patrimônio, formação cultural, políticas municipais, políticas estaduais, entre outros. Vejamos abaixo os dados de 2010 - para uma melhor visualização serão apresentados a tabela (com números absolutos) e o gráfico dos percentuais correspondentes.

Tabela 5 - Local de origem do trabalho - 2012

\begin{tabular}{|l|l|l|}
\hline Localidade & & 1 \\
\hline Argentina & 17 & 15 \\
\hline Bahia & 2 & 1 \\
\hline Brasilia & 4 & 2 \\
\hline Ceará & - & 1 \\
\hline Colômbia & - & 1 \\
\hline Espanha & 2 & - \\
\hline Minas Gerais & - & 2 \\
\hline Pernambuco & 15 & 12 \\
\hline Rio de Janeiro & 1 & - \\
\hline Rio Grande do Sul & 2 & 3 \\
\hline São Paulo & & \\
\hline
\end{tabular}

Fonte: Cds dos Anais dos eventos 
Gráfico 3 - Distribuição geográfica dos trabalhos - ENECULT/2010

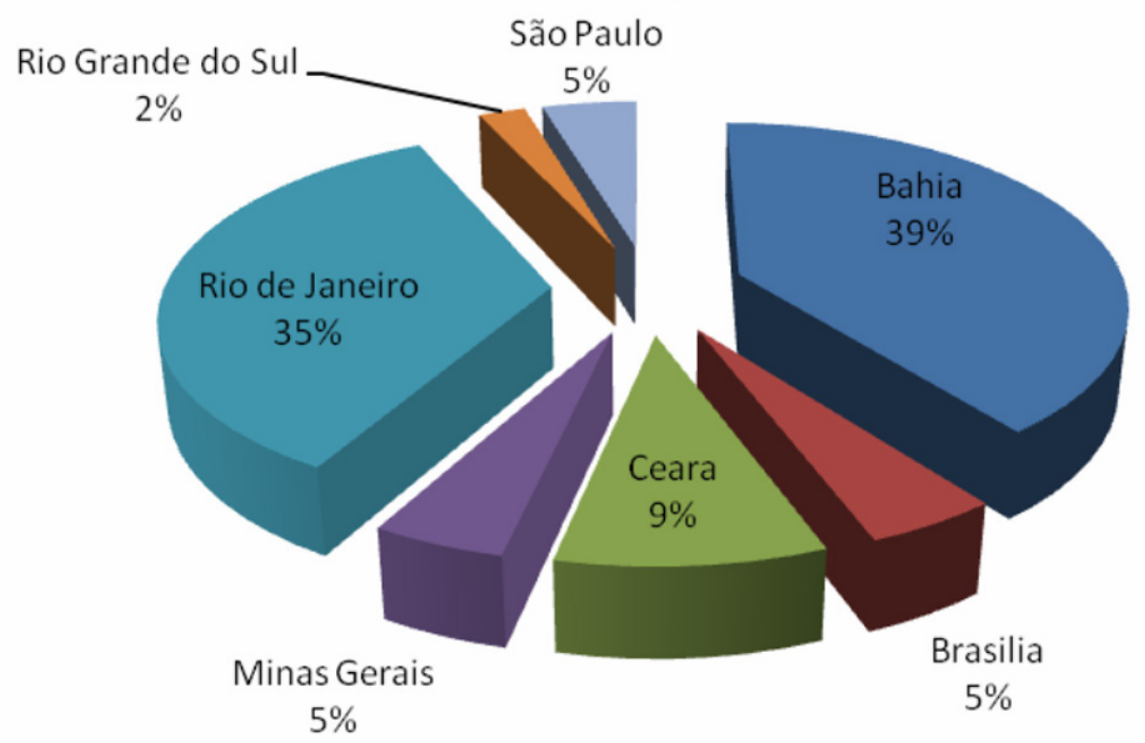

Fonte: Cds dos Anais dos eventos

Gráfico 4 - Distribuição geográfica dos trabalhos recebidos (2010)

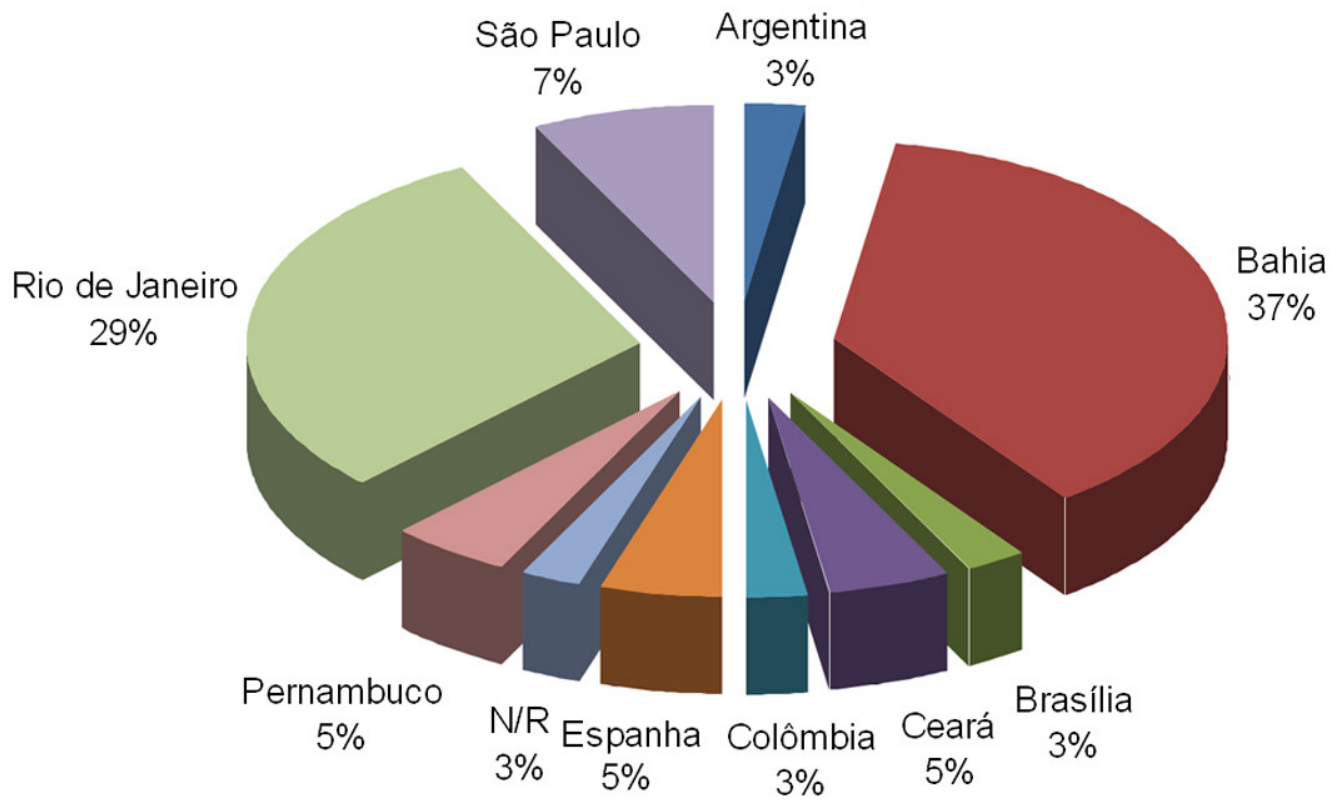

Fonte: Cds dos Anais dos eventos 
Nos dois encontros de 2010 verificamos níveis de concentração e dispersão similares, ou seja, uma concentração de participantes da Bahia e do Rio de Janeiro e uma pulverização de participantes de outros estados, masque, naquele momento, ainda não atinge todas as regiões do país. Por outro lado, uma série de temáticas no campo das políticas culturais também vinham atraindo a atenção de estudantes estrangeiros alguns, inclusive, com bolsas de pesquisa no país. Tal tendência se esboça nos dados sobre os trabalhos apresentados.

Na Bahia há uma predominância dos trabalhos do Programa Multidisciplinar em Cultura e Sociedade da UFBA (mas não é o número total, há presença de outros programas). É importante fazer o registro de que houve uma espécie de concentração de trabalhos em políticas culturais nos primeiros anos do Enecult, tanto do público discente quanto dos docentes, muito em função da proposta da criação de uma possível associação ou um fórum permanente de discussão e pesquisa sobre o tema que acabou não ocorrendo, mas resultou, sem dúvida, no crescimento da presença mais massiva dos alunos nos encontros.

\section{Tabela 6 - Área de formação - 2010}

Quanto ao fenômeno da concentração de trabalhos oriundos do Rio de Janeiro, em parte, deve-se ao Programa de História, política e bens culturais, com dois mestrados (um acadêmico e outro profissional) e um doutorado, do qual se origina uma parte dos estudos na área. Por outro lado, o estado também conta com inúmeros programas de pós-graduação em áreas como antropologia, memória e patrimônio, políticas públicas, comunicação, história, arquitetura, entre outros. Há um número significativo de teses e dissertações sobre políticas culturais sendo produzidas, não só no estado do Rio de Janeiro, de maneira dispersa em várias áreas do conhecimento.

O seminário do setor de políticas culturais da FCRB, nasceu em franco diálogo com o Enecult. A transformação de um seminário organizado só com a presença de palestrantes convidados para um modelo de mesas de comunicação com chamada pública de trabalhos ocorrida no ano de 2010 , foi muito influenciado pelo crescimento de estudos observado em especial no encontro da Bahia.

A tabela abaixo nos fornece um quadro da diversidade das áreas do conhecimento nas quais os trabalhos foram produzidos já em 2010. 


\begin{tabular}{|c|c|c|}
\hline Area de formação & ENECULT & FCRB \\
\hline Ação cultural & 1 & - \\
\hline Administração & 1 & - \\
\hline Antropologia & 2 & 2 \\
\hline Arquitetura & - & 3 \\
\hline Artes Cênicas & - & 2 \\
\hline Ciência da informação & 1 & - \\
\hline Ciências socais & 1 & - \\
\hline Comunicação & 2 & 1 \\
\hline Comunicação e cultura & 2 & - \\
\hline Comunicação social & 1 & - \\
\hline Direito & - & 1 \\
\hline Economia & 2 & - \\
\hline Estudos Culturais & 1 & - \\
\hline $\begin{array}{l}\text { Extensão rural e } \\
\text { desenvolvimento local }\end{array}$ & - & 1 \\
\hline Geografia & - & 1 \\
\hline Gestão do patrimônio & - & 1 \\
\hline História & 3 & 6 \\
\hline $\begin{array}{l}\text { História política e bens } \\
\text { culturais }\end{array}$ & 1 & - \\
\hline Letras & 1 & 1 \\
\hline $\begin{array}{l}\text { Multidisciplinar em cultura } \\
\text { e sociedade }\end{array}$ & 13 & 12 \\
\hline Música & 2 & 1 \\
\hline $\begin{array}{l}\text { Políticas públicas e } \\
\text { sociedade }\end{array}$ & 2 & 1 \\
\hline Políticas sociais & 1 & - \\
\hline Relações internacionais & 1 & 1 \\
\hline Serviço social & 1 & - \\
\hline Sociologia & 4 & 2 \\
\hline Sem resposta & 1 & 1 \\
\hline
\end{tabular}

Fonte: Cds dos Anais dos eventos 


\section{Gráfico 5 - Área de formação - ENECULT/2010}

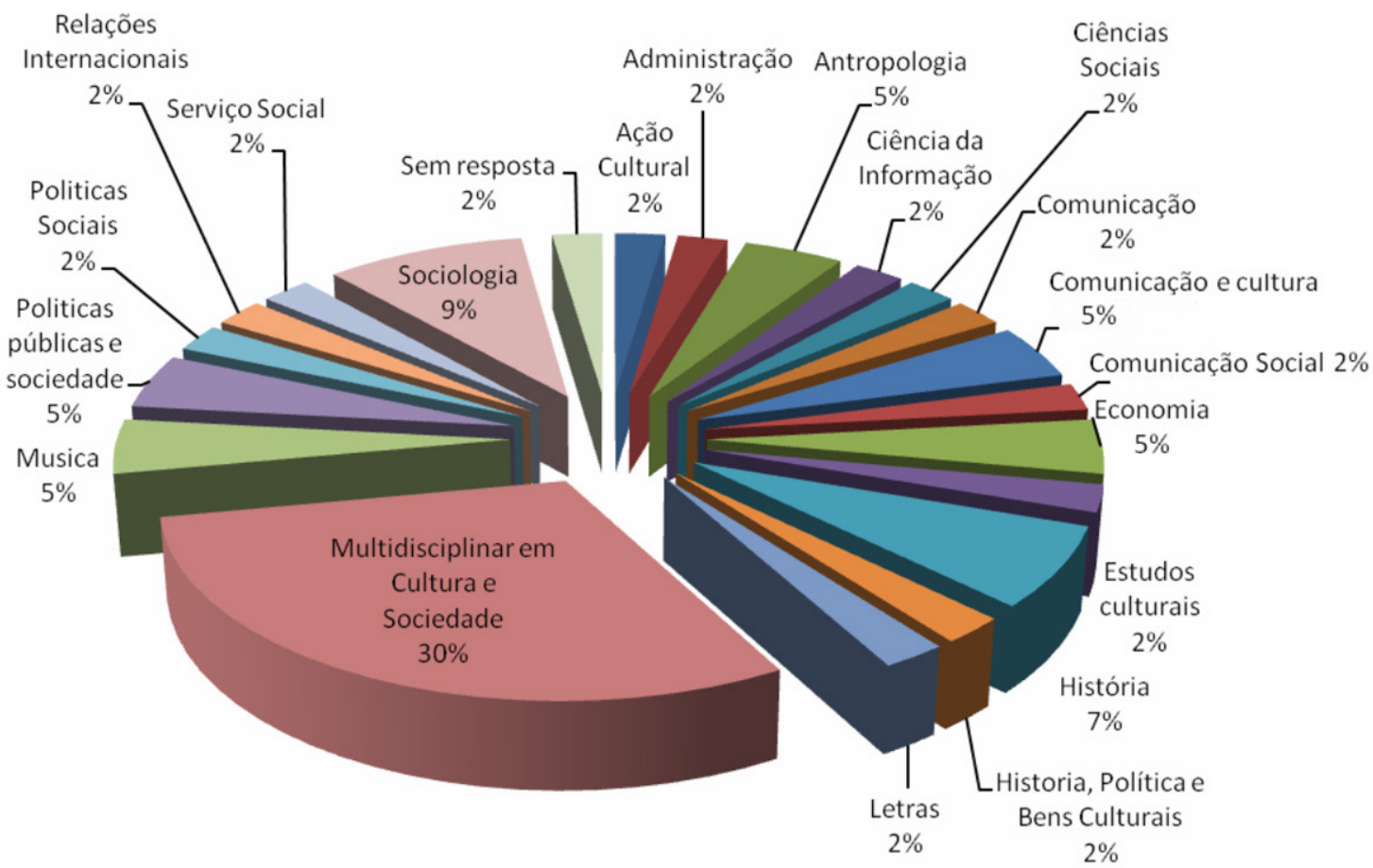

Fonte: Cds dos Anais dos eventos

\section{Gráfico 6 - Área de formação dos participantes (2010) FCRB}

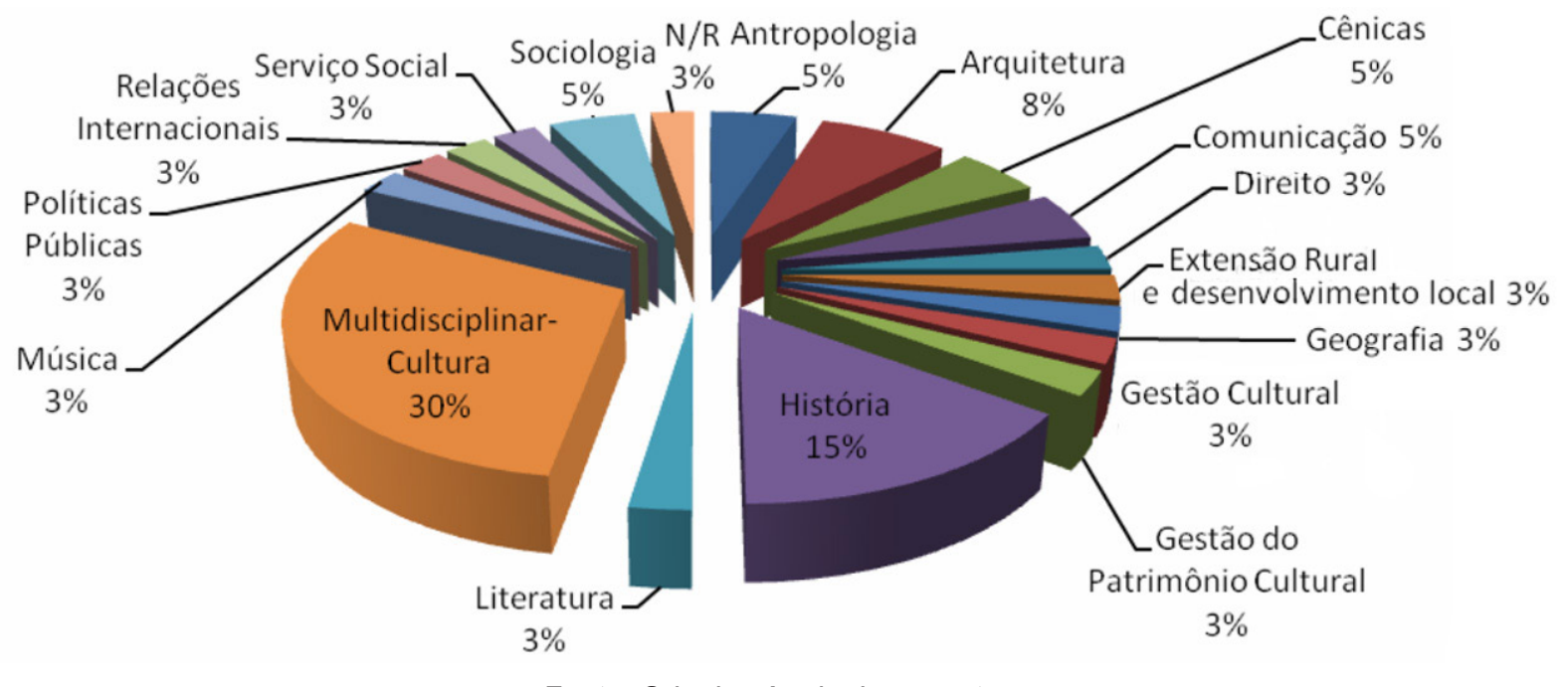

Fonte: Cds dos Anais dos eventos

Para o mapeamento das áreas foram consideradas as áreas de todos os autores dos artigos, pois encontros acadêmicos verificamos que é comum que alguns dos artigos seja elaborado por mais de um autor, fato que aumenta o universo pesquisado. No total acima apresentado há 26 áreas citadas, 
sendo que algumas delas claramente agregáveis pela grande área, mas foram respeitadas as especificidades dos programas informados pelos autores dos artigos. É interessante destacar que o curso multidisciplinar da UFBA, mantém a identidade no nome do próprio curso e que alguns outros tem um recorte de área mas pertencemà grande área multidisciplinar - que como vimos no gráfico da Capes passou de menor grande área em 2000 para a terceira colocação em $2012^{12}$.

Passamos agora para os dados de 2012.

Tabela 7 - Local de origem dos trabalhos - 2012

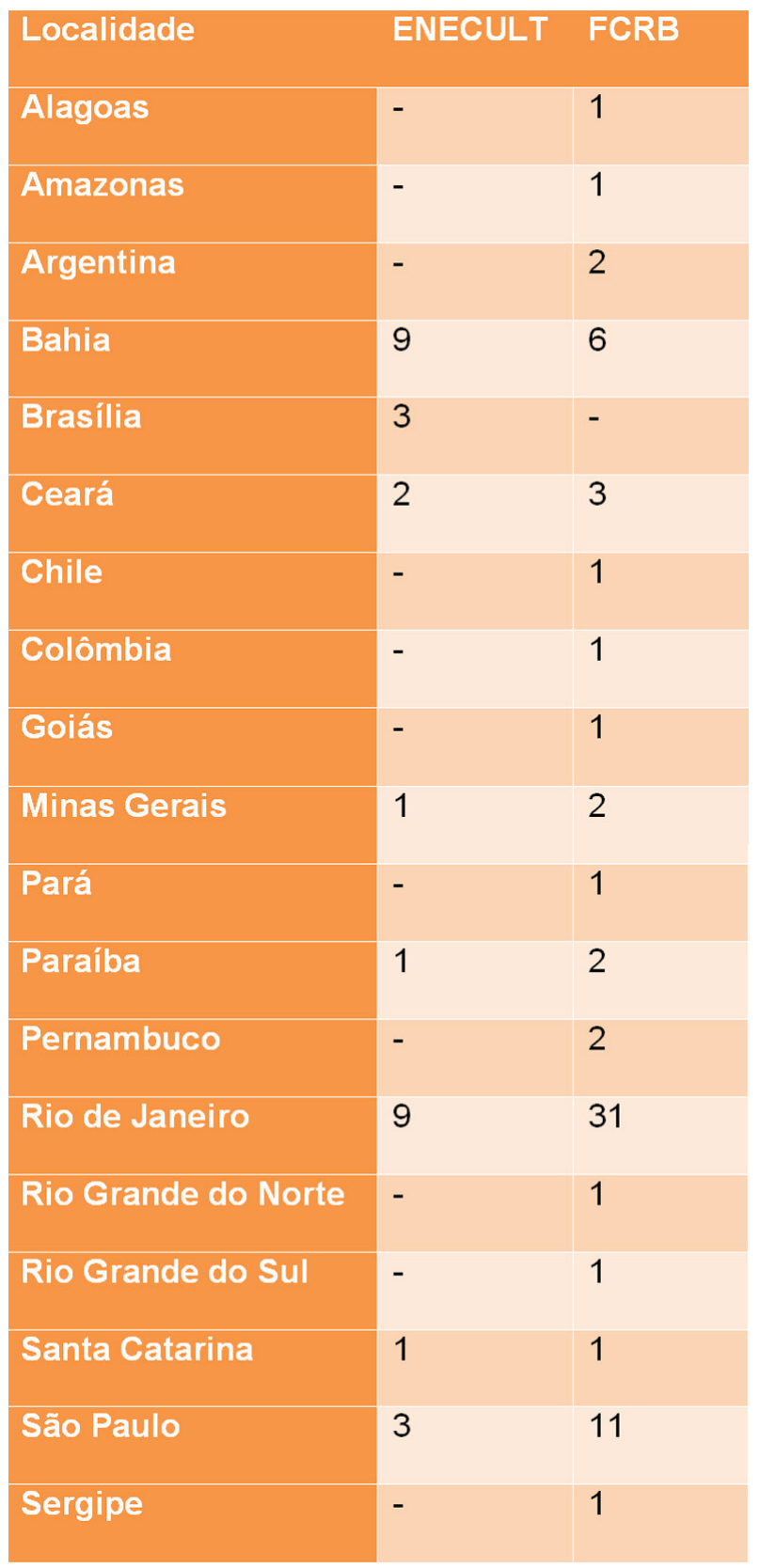

Fonte: Cds dos Anais dos eventos 


\section{Gráfico 7 - Distribuição geográfica - ENECULT/20102}

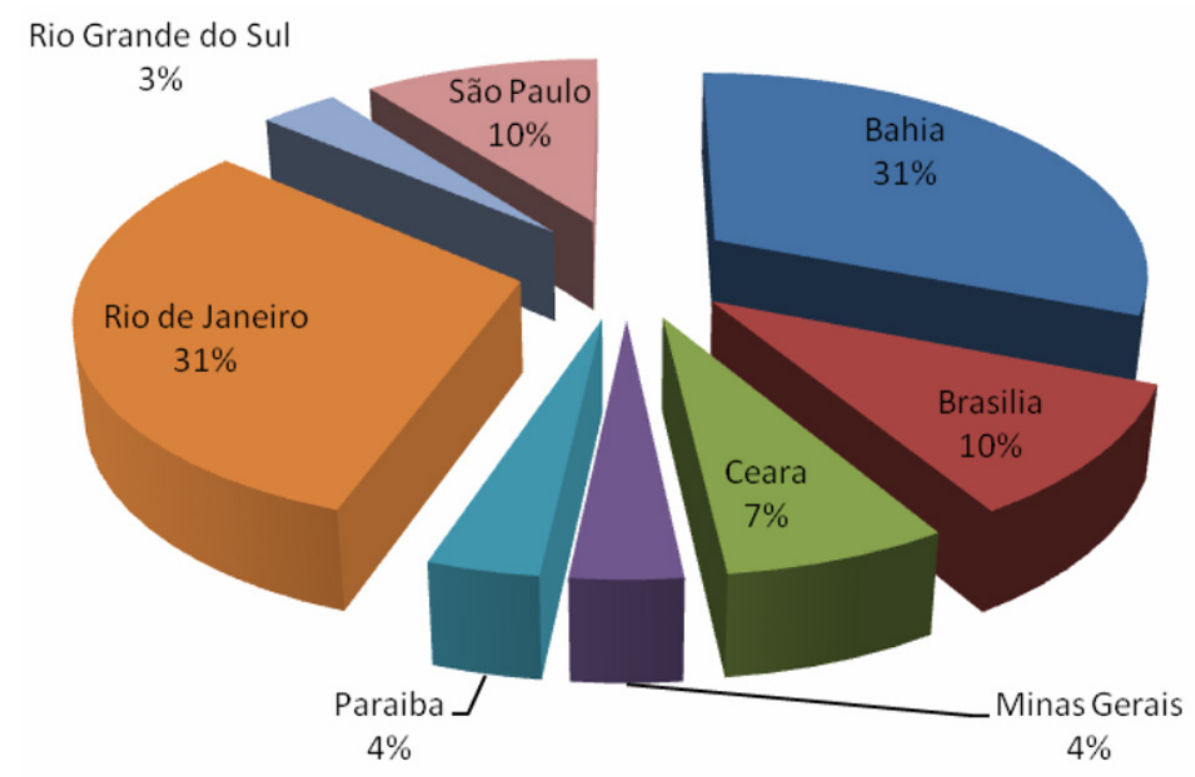

Fonte: Cds dos Anais dos eventos

Gráfico 8 - Distribuição geográfica dos trabalhos recebidos - (2012) FCRB

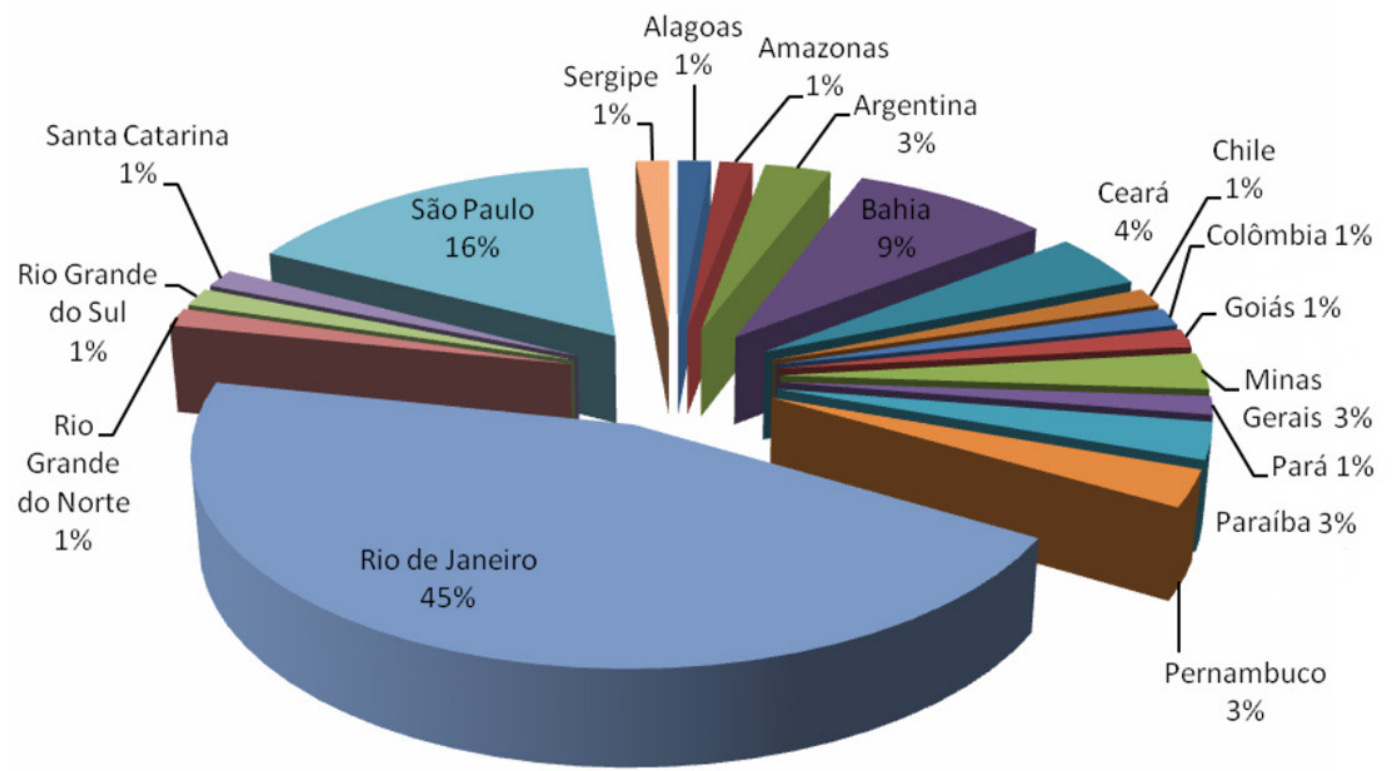

Fonte: Cds dos Anais dos eventos 
O quadro acima aponta para uma significativa ampliação da presença do tema políticas culturais na produção acadêmica distribuída pelo conjunto das regiões brasileiras. Também se percebe um crescimento do diálogo com os países latino-americanos, com a presença de estudantes e profissionais apresentando, em geral, as experiências de seus países de origem. Podemos propor como hipótese para tal quadro, por um lado, a ampliação das ações do Ministério da Cultura que provocaram efetivos impactos nas diversas regiões do país e, por outro, a presença mais constante do tema em documento e fóruns de organismos internacionais, como a Unesco (ou a Unctad), de alguma maneira promovendo experiências que passam a chamar a atenção dos especialistas a ponto de se tornarem objetos de estudo acadêmico.

Tal fenômeno de expansão vai também ser observado nos dados a seguir sobre as áreas de formação dos proponentes de trabalhos. Um fenômeno importante a ressaltar é o da diminuição de trabalhos apresentados no GT de políticas culturais no Enecult, que corresponde para a migração de parte dessa discussão para os grupos dedicados a um recorte específico tais como audiovisual, mídia ou território. Muitos desses trabalhos que estão dispersos no Enecult participam com recortes específicos de políticas culturais no seminário da FCRB.

\section{Tabela 7 - Local de origem dos trabalhos - 2012}

\begin{tabular}{|l|ll}
\hline Área de Formação & ENECULT & FCRB \\
\hline Administração & 1 & 2 \\
\hline Antropologia & - & 4 \\
\hline Arquitetura & - & 2 \\
\hline Ciência da Informação & - & 1 \\
\hline Ciência Política & 1 & 2 \\
\hline Ciências Sociais & 2 & 4 \\
\hline Comunicação & 4 & 8 \\
\hline Design & - & 2 \\
\hline Economia & - & 2 \\
\hline Educação & 1 & 3 \\
\hline Gestão de Projetos & 1 & - \\
\hline Gestão Pública & 1 & - \\
\hline Engenharia de Produção & - & 1 \\
\hline Geografia & - & 1 \\
\hline
\end{tabular}


pragMATIZES - Revista Latino Americana de Estudos em Cultura

\begin{tabular}{|c|c|c|}
\hline História & 2 & 8 \\
\hline Imagem e som & - & 1 \\
\hline Letras & 1 & 1 \\
\hline Meio Ambiente & - & 1 \\
\hline Memória Social e Patrimônio & 1 & - \\
\hline $\begin{array}{l}\text { Multidisciplinar - sociedade e } \\
\text { cultura }\end{array}$ & 7 & 5 \\
\hline $\begin{array}{l}\text { Multidisciplinar - Estudos } \\
\text { Culturais }\end{array}$ & - & 2 \\
\hline Multidisciplinar - Memória Social & - & 1 \\
\hline Multidisciplinar & - & 2 \\
\hline Museologia & - & 4 \\
\hline Patrimônio e Bens Culturais & 1 & - \\
\hline $\begin{array}{l}\text { Políticas e Instituições } \\
\text { Educacionais }\end{array}$ & - & 1 \\
\hline Políticas Públicas & - & 1 \\
\hline Políticas Sociais & 2 & - \\
\hline Psicologia & 1 & 2 \\
\hline Relaçōes Internacionais & - & 1 \\
\hline Sociologia & 2 & 5 \\
\hline $\begin{array}{l}\text { Teoria y Metodologia de las } \\
\text { ciências sociales }\end{array}$ & - & 1 \\
\hline Turismo & - & 1 \\
\hline N/R & - & 3 \\
\hline
\end{tabular}

Fonte: Cds dos Anais dos eventos 


\section{Gráfico 9 - Área de formação - ENECULT/2012)}

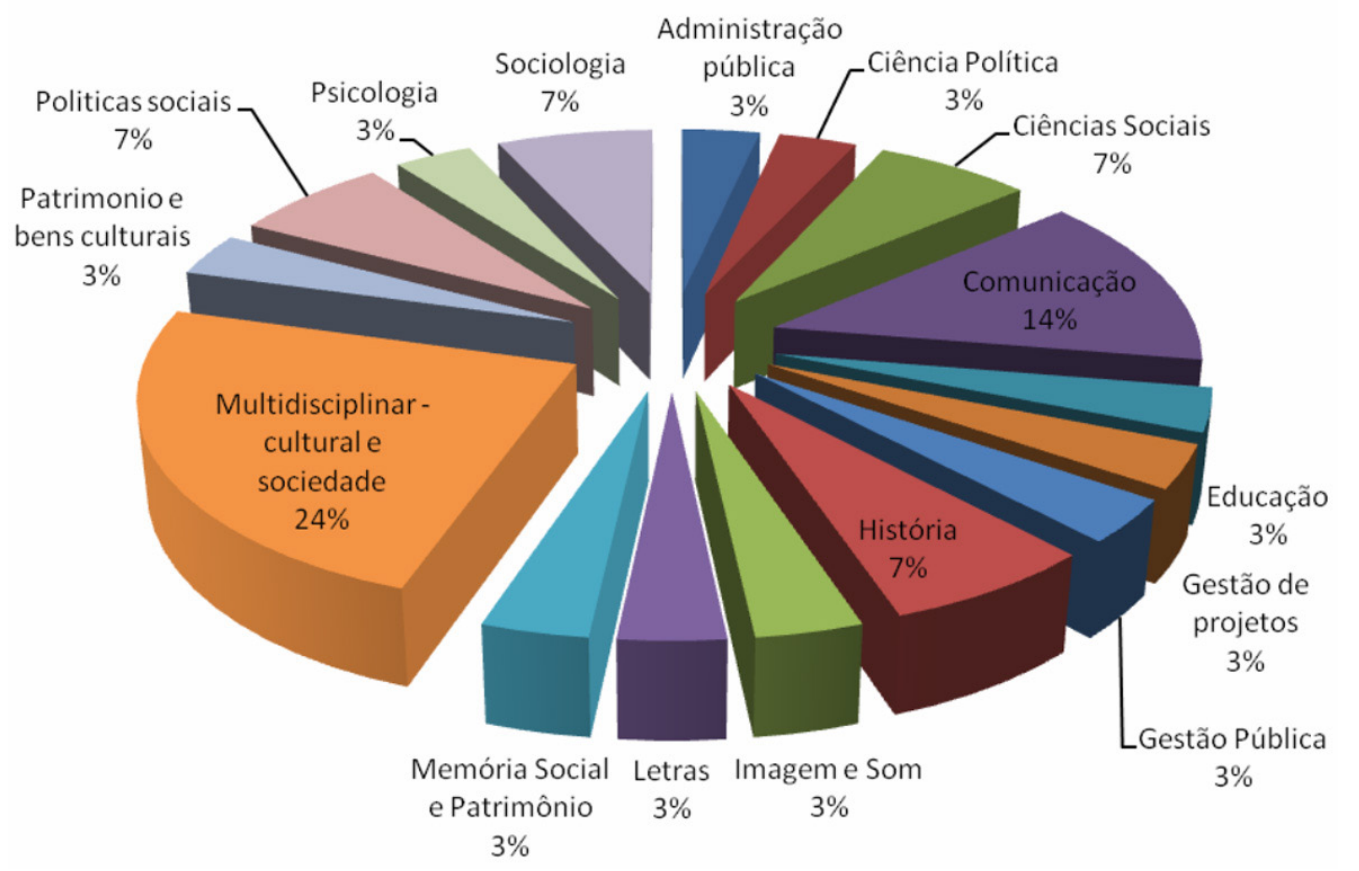

Fonte: Cds dos Anais dos eventos

\section{Gráfico 10 - Área de formação (2012)FRCB}

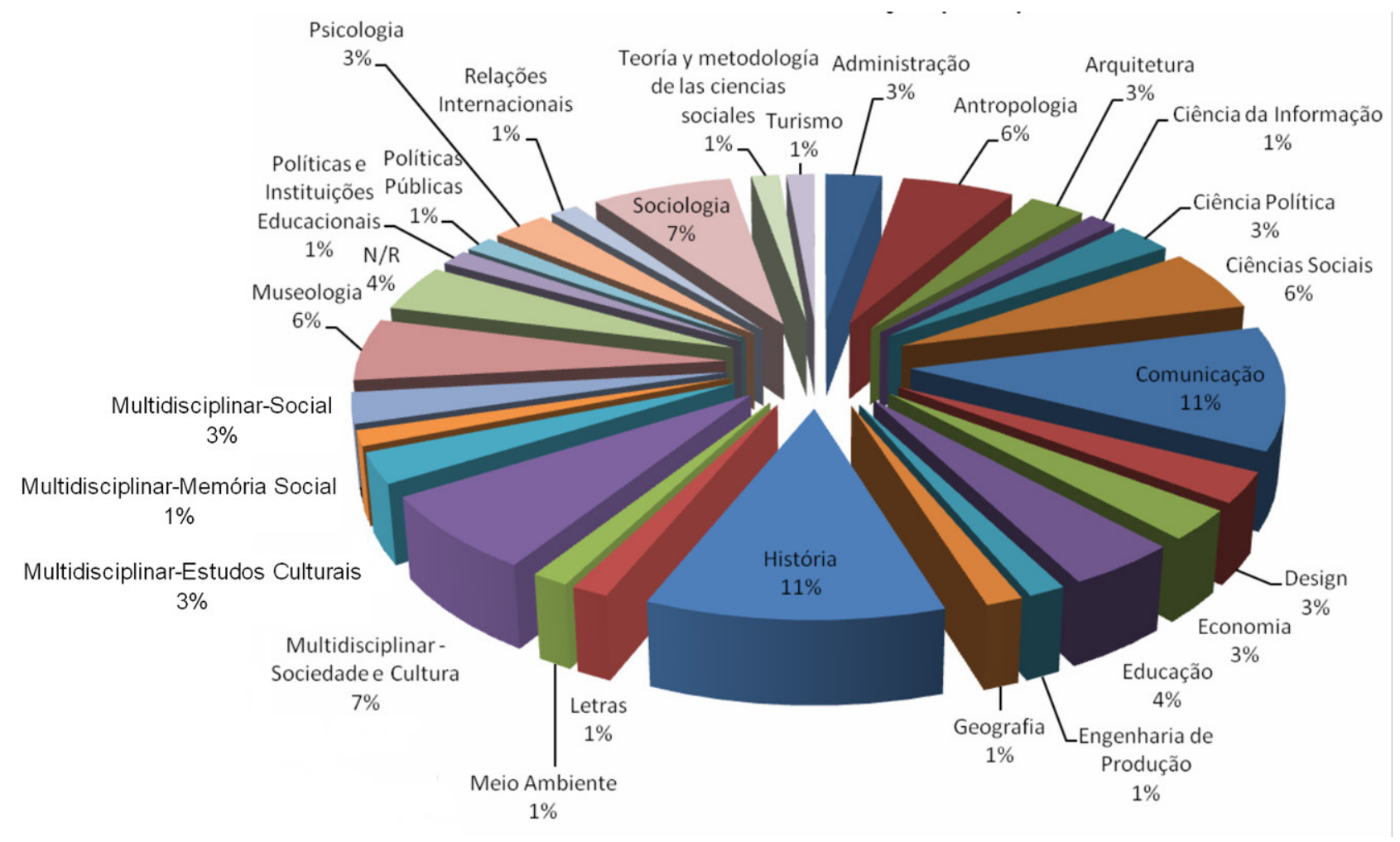

Fonte: Cds dos Anais dos eventos 
Os dados acima nos apresentam um cenário de crescente dispersão dos trabalhos sobre políticas culturais em campos disciplinares muito diversos e, arriscaria afirmar, até pouco prováveis como o da psicologia social. Temos 33 campos distintos listados, com uma dispersão maior dos trabalhos entre os mesmos, com o maior número de trabalhos nos mestrados multidisciplinares, na comunicação e na história. Mas já com a presença da ciência política, da administração e da gestão pública.

\section{Algumas questões à guisa de conclusão}

A dispersão da produção dos trabaIhos, apontada pelos levantamentos aqui apresentados, em áreas muito diversas, tem aspectos positivos e negativos. Por um lado podemos dizer que levando em conta que o conceito ampliado de cultura na gestão pública, que vem sendo proposto pelo Ministério da Cultura para as ações desenvolvidas no campo das políticas públicas, propicia, ou melhor, requer olhares disciplinares múltiplos. Tal abordagem sobre as ações e objetos culturais é ainda muito nova, especialmente quando pensamos em consolidação de campos de conhecimento. Se os múltiplos olhares, por um lado, produzem um espectro amplo e variado de análise, por outro, as torna muito solitárias no seu campo disciplinar, algumas vezes até mesmo pouco compreendidas. Dentro de uma lógica de encontros acadêmicos que mantém uma estrutura mais rígida com foco da área de formação, tais trabalhos ficam com poucos canais de debate. É importante ressaltar que algumas áreas como a antropologia e a sociologia, com uma tradição de manter objetos de estudo de um universo mais variado têm permitido o surgimento de GTs que também tratam de políticas culturais. Em compensação verificamos que algumas outras áreas mantêm estruturas muito rígidas. Um exemplo preocupante é o da quase completa ausência de trabalhos sobre políticas de cultura nos seminários de gestão e administração pública, mesmo com o quadro diversos de trabalhos que vimos acima - mas que são produzidos majoritariamente em um campo fora da administração.

Nessa conjuntura amplia-se a importância da existência dos encontros com cortes temáticos, não rigidamente disciplinares, para propiciar efetivos diálogos entre trabalhos produzidos originalmente em campos muito distantes e que tradicionalmente não teriam como manter relações.

É inegável o importante papel cumprido pelas políticas do Ministério da Cultura, que começaram a ser implementadas a partir de 2003, para a ampliação do conjunto dos estudos acadêmicos. Porém, é importante ressaltar que experiências como a de Mário de Andrade em São Paulo, na década de 1930, ou da gestão da Marilena Chauí como secretária de cultura, das leis municipais e estaduais (assim como as federais) de incentivo, ou ainda as políticas de patrimônio, que já vinham sendo estudadas desde a década de 1990, também tem sido revisitadas por novas pesquisas.

O levantamento demonstra a existência de uma massa considerável de trabalhos e que talvez já seja possível a realização de algumas análises com base em fontes secundárias para, por exemplo, a composição de um quadro da história das políticas culturais no Brasil a partir dos anos 2000. Consideramos igualmente importante a realização de análises dessa massa de informações que estão disponíveis nas teses e dissertações, de maneira a produzir subsídios para o estado no processo construção e aperfeiçoamento de política públicas de cultura.

Novos encontros com propostas e recortes diferenciados tem surgido, como o Encontro Brasileiro de Pesquisa em Cul- 
tura, que tem caráter itinerante e acabou de realizar o II Encontro Nacional, no qual as questões propostas no presente artigo foram discutidas em uma roda de conversa.

Enfim: - Vida longa aos encontros e seminários consolidados e que se multipliquem as novas propostas e os novos e diferenciados espaços de discussão.

\section{Bibliografia}

VI ENECULT - Encontro de Estudos Multidisciplinares em Cultura. Anais - CD Rom. Salvador, UBFA, 2010

VIII ENECULT - Encontro de Estudos Multidisciplinares em Cultura. Anais - CD Rom. Salvador, UBFA, 2012

GEOCAPES. Disponível em: http://geocapes. capes.gov.br/geocapesds/\#app=c501\&da7a-selectedIndex $=0 \& 5317$-selectedlndex $=0 \& \mathrm{dbcb}$ -selectedlndex=0. Capturado em 20/11/2014.

RUBIM, Linda; Veira, Mariella e Souza, Delmira de (org.) Enecult 10 anos. Salvador: Edufba, 2014.

SEMINÁRIO Internacional políticas culturais: teoria e práxis. Anais - CD Rom. Rio de Janeiro, FCRB, 2010.

III SEMINÁRIO Internacional políticas culturais. Anais - CD Rom. Rio de Janeiro, FCRB, 2012

1 Doutora em história (UFF), pesquisadora e chefe do setor de estudos de políticas culturais de Fundação Casa de Rui Barbosa / FCRB. Contato: liacalabre@rb.gov.br

2 Criado em 2003. Ver: http://www.cult.ufba.br/ wordpress/

3 Em 2005 o IHAC ainda não existia e o encontro era promovido pela Faculdade de Comunicação FACOM, onde foi criado em 1996 o Curso de Produção e Organização da Cultura.
4 A pesquisa aqui utilizada foi realizada no primeiro semestre de 2013, quando a base de dados da Capes disponibilizava informações desde 1987. No segundo semestre de 2014 a ordenação da base foi alterada e a Capes decidiu rever todas as informações retirando a base antiga do ar. No novo formato foram disponibilizadas, inicialmente as informações de 2012, em seguida foram incluídas as de 2011, com o compromisso de inclusão gradativa dos anos anteriores. Mais informações consultar http://bancodeteses.capes.gov.br/noticia/view/id/1

5 Um estudo mais detalhado das teses e dissertações defendidas especificamente nos anos de 2011 e 2012, está sendo preparado.

$6 \mathrm{Na}$ tabela foram trabalhados os três anos com o objetivo de propiciar a ampliação da percepção das tendências das temáticas e das nomenclaturas.

7 Em 2010 e 2011 o termo cultura foi colocado no singular, no ano de 2012 no plural

8 Esse é inclusive o meu caso, que somente passei a trabalhar com as políticas culturais após o término da tese de doutoramento sobre rádio e sociedade.

9 A base na época disponibilizava dados a partir de 1987, mas nesse ano nenhum registro contendo as palavras-chave foi encontrado.

10 A base Geocapes mapeia os programas a partir de 1998, tendo em vista a maneira como foi organizada a distribuição das tabelas no presente artigo e da ausência de informações sobre 1988, optou-se por trabalhar com os dados de 2000 e 2012, anos limites dos recortes temporais.

11 Ver: http://geocapes.capes.gov. br/geocapesds/\# a p p = c 501 \& d a 7 a - selectedindex $=0 \& 5317$ - selectedIn$d e x=0 \& d b c b-$ selected Index $=0$

12 Esse é um outro fenômeno que merece ser estudado profundamente, mas que não é objetivo do presente artigo. 